\title{
Pengaruh Persepsi Tentang Identitas Profesi Terhadap Sikap Interprofessional Collaboration Tenaga Kesehatan di Puskesmas
}

\author{
Eti Poncorini Pamungkasari ${ }^{1}$, Sri Anggarini Parwatiningsih ${ }^{2}$ \\ 1. Program Studi Kedokteran, Fakultas Kedokteran, Universitas Sebelas Maret Surakarta \\ 2. Program Studi Kebidanan, Fakultas Kedokteran, Universitas Sebelas Maret Surakarta
}

Korespondensi : etiponco@staff.uns.ac.id

\begin{abstract}
ABSTRAK
Pendahuluan: Kolaborasi tenaga medis merupakan hal yang penting dalam mengupayakan peningkatan kualitas pelayanan kesehatan. WHO menyampaikan bahwa kolaborasi akan memperkuat sistem kesehatan. Studi tentang kolaborasi tenaga medis di Indonesia terutama tentang tenaga medis Puskesmas masih sangat terbatas.

Metode: Studi ini merupakan bagian dari pengabdian masyarakat, dengan pendekatan cross sectional. Lokasi yang digunakan adalah Puskesmas Banyuanyar dan Puskesmas Kratonan, mewakili Puskesmas di kawasan pedesaan dan perkotaan. Tenaga kesehatan yang mengikuti kegiatan ini sebanyak 37 orang. Instrumen yang digunakan adalah kuesioner persepsi tentang identitas profesi, dan kuesioner sikap tentang interprofessional collaboration. Data yang didapatkan dianalisis statistik dengan uji regresi linier ganda.

Hasil: Setiap peningkatan satu skor persepsi tentang identitas profesi akan meningkatkan sikap interprofessional collaboration sebesar 1,07; dan signifikan secara statistik $(\mathrm{p}=$ 0,001 ), setiap peningkatan satu tahun lama kerja akan menurunkan sikap interprofessional collaboration, namun tidak signifikan secara statistik $(\mathrm{p}=0,31)$. Persepsi tentang identitas profesi dan lama kerja bersama-sama mempengaruhi sikap interprofessional collaboration sebesar $31 \%$, sisanya sebesar $69 \%$ dipengaruhi oleh faktor lain yang tidak diteliti, model regresi ganda fit dengan $\mathrm{p}=0,001$.

Kesimpulan: Persepsi tenaga kesehatan tentang identitas profesi mempengaruhi sikap tentang identitas profesi. Perlu memperkuat persepsi tenaga kesehatan tentang identitas profesi.
\end{abstract}

Kata Kunci: kolaborasi; puskesmas; tenaga medis; identitas profesi

\begin{abstract}
Introduction: Collaboration of health care workers is important in order to improve the quality of health services. WHO states that collaboration will strengthen the health system. Studies on collaboration of health care workers in Indonesia, especially on public health center workers, are still very limited.

Methods: This study was part of community service, with a cross sectional study approach. The locations used are Puskesmas Banyuanyar and Puskesmas Kratonan, representing public health center in rural and urban areas. There were 37 health workers who participated in this activity. The instrument used was a perception of professional identity, and attitudes about interprofessional collaboration. The data obtained were statistically analyzed using the multiple linear regression.

Results: Every increase of one perception score about professional identity would increase interprofessional collaboration attitude by 1.07, statistically significant $(p \leq 0.001)$, every increase of one year of work would decrease interprofessional collaboration attitude, but not statistically significant $(p=-0.31)$. Perceptions of professional identity and length of work together affect interprofessional collaboration attitude by $31 \%$, the remaining $69 \%$ is influenced by other factors not examined, the multiple fit regression model with $p=0.001$.
\end{abstract}


Conclusion: Health workers' perceptions about professional identity influence attitudes about professional identity. There is a need to strengthen the perception of health workers about professional identity.

\section{Keywords: collaboration; public health center; health care workers; professional identity}

\section{PENDAHULUAN}

Kolaborasi tim kesehatan merupakan hal yang penting dalam pelayanan kesehatan. Telah banyak bukti bahwa mutu pelayanan dapat ditingkatkan dengan kolaborasi yang baik. Kolaborasi tim kesehatan yang tidak berjalan baik dapat mengakibatkan medical error. Konsep interprofessional education dan collaboration (IPEC) saat ini mulai banyak diperkenalkan pada pelayanan kesehatan, sesuai dengan harapan dari World Health Organization (WHO). IPEC terjadi ketika dua atau lebih profesi kesehatan belajar atau bekerja bersama. Elemen yang penting dalam kolaborasi antara lain tanggung jawab, akuntabilitas, komunikasi, koordinasi, assertiveness, saling percaya, saling menghargai ${ }^{1}$.

Pelayanan kesehatan mengalami perubahan karena berbagai faktor, antara lain adalah karena perubahan demografi, model pelayanan kesehatan baru, kemajuan teknologi bidang kesehatan, peningkatan spesialisasi di bidang kesehatan, keamanan pasien dan tekanan di tempat kerja ${ }^{2}$. Interprofessional Education (IPE) menjadi hal penting saat ini dalam pembelajaran di bidang kesehatan. Definisi IPE adalah situasi saat dua atau lebih profesi belajar bersama, dari dan tentang satu sama lain untuk meningkatkan kolaborasi dan kualitas pelayanan ${ }^{3,4}$. Implementasi IPE diharapkan akan meningkatkan kualitas pelayanan kesehatan dan mengurangi kesalahan-kesalahan medis (medical errors). Walaupun banyak institusi pendidikan kesehatan masih menemui kendala dalam implementasi IPE, hasil studi terdahulu menunjukkan bahwa IPE dapat dilakukan, dan mempunyai peran dalam penentuan tugas dan tanggungjawab masing-masing profesi kesehatan ${ }^{5}$. Tujuan pembelajaran yang ada dalam IPE menurut salah satu sistematik review, antara lain mencakup kerjasama tim, peran dan tanggungjawab, komunikasi, refleksi dalam pembelajaran pasien misalnya tentang keselamatan pasien (patient safety) etika dan perilaku ${ }^{6}$.

Penelitian menunjukkan bahwa di seluruh dunia masih perlu dikembangkan IPEC. Misalnya dalam aspek komunikasi, masih banyak tenaga kesehatan yang belum bisa berkomunikasi secara baik dengan profesi lain yang bekerja sama dalam satu tim kesehatan ${ }^{7}$. Salah satu penyebabnya adalah tenaga kesehatan yang saat ini bekerja di masyarakat belum dilatih secara formal tentang IPEC dalam kurikulum pendidikannya dulu. Penelitian terdahulu menyebutkan bahwa perawat lulusan kurikulum dengan pembelajaran IPE mampu melakukan kolaborasi lebih baik dibandingkan lulusan kurikulum tanpa pembelajaran IPE ${ }^{8}$. Sekarang ini pendidikan kesehatan dihimbau untuk memasukkan IPEC dalam kurikulum, untuk itu dibutuhkan tenaga kesehatan yang mampu berperan menjadi kolaborator yang baik, karena tenaga kesehatan menjadi role model bagi mahasiswa dalam pembelajaran IPEC. Beberapa profesi kesehatan, misalnya dokter umum masih belum dapat memahami dan melaksanakan nilai-nilai penting dalam IPEC ${ }^{9}$. Fakultas Kedokteran Universitas Sebelas Maret Surakarta saat ini melaksanakan kurikulum interprofessional education dan collaboration komunitas. Kegiatan pembelajaran dilakukan di wilayah Puskesmas di beberapa Kabupaten dan Kota. Aktifitas pembelajaran ini melibatkan tenaga medis di Puskesmas sebagai pembimbing. Tenaga 
medis yang ada di Puskesmas saat masa pendidikannya dahulu belum menjalani kurikulum yang mengajarkan tentang IPEC, sementara role model sangat penting dalam pembelajaran IPE. Untuk itulah kegiatan pengabdian masyarakat ini penting, untuk memberikan pemahaman pada tenaga medis tentang IPEC dan mengukur seberapa besar identitas profesi mempengaruhi sikap tenaga medis tentang kolaborasi.

\section{METODE}

Dilakukan pengabdian masyarakat di dua Puskesmas di Kotamadya Surakarta, masing masing mewakili Puskesmas dengan letak geografis kawasan pinggiran kota dan tengah kota Surakarta. Tenaga kesehatan yang mengikuti kegiatan ini sebanyak 37 orang, sampel diambil secara purposif sampling. Kriteria yang ditetapkan adalah tenaga kesehatan yang saat pengambilan data sedang berada di Puskesmas. Pada pengabdian masyarakat ini, tenaga kesehatan diberi paparan tentang interprofessional education dan collaboration, kemudian diminta mengisi kuesioner. Kuesioner tersebut adalah persepsi tentang identitas profesi, dan sikap tentang interprofessional collaboration. Kuesioner telah diuji validitas dan reliabilitasnya, dengan hasil alpha Chronbach untuk persepsi tentang identitas profesi adalah 0.92, dan sikap tentang interprofessional collaboration adalah 0,90 .
Selain itu responden juga mengisi identitas diri berupa umur, jenis kelamin, lama kerja dan pendidikan terakhir. Data yang didapatkan dianalisis statistik dengan uji regresi linier ganda.

Tabel 1. Karakteristik responden berdasar jenis kelamin, profesi dan pendidikan terakhir

\begin{tabular}{lcc}
\hline & Frekuensi & Persentase \\
\hline $\begin{array}{l}\text { Jenis } \\
\text { Kelamin }\end{array}$ & & \\
Laki-laki & 6 & 16,2 \\
Perempuan & 31 & 83,8 \\
Profesi & & \\
Dokter dan & 5 & 13,5 \\
dokter gigi & & \\
Perawat & 10 & 27,0 \\
Bidan & 5 & 13,5 \\
Farmasi & 4 & 10,8 \\
Kesmas & 2 & 5,4 \\
Lainnya & 11 & 29,7 \\
Pendidikan & & \\
terakhir & & \\
\multicolumn{1}{c}{ D3 } & 19 & 51,4 \\
D4 & 3 & 8,1 \\
S1 & 15 & 40,5 \\
Profesi & &
\end{tabular}

Profesi lain yang dimaksud pada tabel diatas adalah rekam medis, bagian pendaftaran dan fisioterapis.

Tabel 2. Karakteristik responden berdasar umur, lama kerja, skor persepsi tentang identitas profesi, dan skor sikap IPC

\begin{tabular}{lcccccc}
\hline & N & Range & Minimum & Maximum & Mean & $\begin{array}{c}\text { Standar } \\
\text { deviasi }\end{array}$ \\
\hline Umur & 37 & 33 & 23 & 56 & 38.35 & 10.52 \\
Lama kerja & 37 & 144 & 1 & 145 & 18.84 & 23.77 \\
$\begin{array}{l}\text { Skor Persepsi } \\
\text { tentang identitas } \\
\text { profesi }\end{array}$ & 37 & 24 & 12 & 36 & 26.43 & 4.99 \\
\begin{tabular}{l} 
Skor sikap IPC \\
\hline
\end{tabular} & 37 & 50 & 77 & 127 & 110.16 & 10.11 \\
\hline
\end{tabular}


Pamungkasari \& Parwatiningsih, Pengaruh Persepsi Tentang Identitas Profesi Terhadap Sikap Interprofessional Collaboration Tenaga Kesehatan di Puskesmas

Tabel 3. Pengaruh persepsi tentang identitas profesi dan lama kerja terhadap sikap interprofessional collaboration

\begin{tabular}{lclll}
\hline Variabel & $\beta$ & $\mathrm{p}$ & \multicolumn{2}{c}{ CI 95 \% } \\
\cline { 4 - 5 } & $\begin{array}{c}\text { (Koefisien } \\
\text { regresi) }\end{array}$ & & $\begin{array}{r}\text { Batas } \\
\text { bawah }\end{array}$ & $\begin{array}{c}\text { Batas } \\
\text { atas }\end{array}$ \\
\hline Konstanta & 83,13 & & & \\
Persepsi tentang & 1,07 & 0,001 & 0,47 & 1,66 \\
Identitas Profesi & & & & \\
Lama kerja & $-0,06$ & 0,310 & $-0,31$ & 0,06 \\
N observasi & 37 & & & \\
Adjusted R2 & 0,310 & & & \\
P model & $\leq 0,001$ & & \\
\hline
\end{tabular}

Interpretasi hasil dengan uji statistik regresi linier ganda didapatkan setiap peningkatan satu skor persepsi tentang identitas profesi akan meningkatkan sikap interprofessional collaboration sebesar 1,07, signifikan secara statistik ( $\mathrm{p}=0,001)$, setiap peningkatan satu tahun lama kerja akan menurunkan sikap interprofessional collaboration, namun tidak signifikan secara statistik $(\mathrm{p}=-0,31)$. Persepsi tentang identitas profesi dan lama kerja bersama-sama mempengaruhi sikap interprofessional collaboration sebesar $31 \%$, sisanya sebesar 69 $\%$ dipengaruhi oleh faktor lain yang tidak diteliti, model regresi ganda fit dengan $\mathrm{p} \leq 0,001$.

\section{PEMBAHASAN}

Pada penelitian ini didapatkan setiap peningkatan satu skor persepsi tentang identitas profesi akan meningkatkan sikap interprofessional collaboration sebesar 1,07; signifikan secara statistik $(\mathrm{p}=0,001)$. Di Indonesia telah diterbitkan Undang-undang terkait praktik profesi kesehatan. Identitas profesi dan pembagian tugas masing-masing profesi sudah ditetapkan dalam undang undang dan peraturan menteri terkait. Undang-undang tersebut antara lain adalah Undang Undang nomor 36 tahun 2014 tentang tenaga kesehatan 10, Undang-undang no 29 tahun 2004 tentang Praktik Kedokteran ${ }^{11}$, Undang-undang no 4 tahun 2019 tentang Kebidanan 12, Undangundang no 38 tahun 2014 tentang Keperawatan 13. Dengan adanya Undang-Undang ini diharapkan dapat menunjang kolaborasi yang baik pada tenaga kesehatan. Dalam salah satu Undang-undang yaitu UU no 36 tahun 2014 disebutkan bahwa tenaga kesehatan terdiri dari tenaga medis (dokter, dokter gigi, dokter spesialis dan dokter gigi spesialis), tenaga psikologi klinis, tenaga keperawatan, tenaga kebidanan, tenaga kefarmasian, tenaga kesehatan masyarakat, tenaga kesehatan lingkungan, tenaga gizi, tenaga keterapian fisik, tenaga keteknisian medis, tenaga teknik biomedika, tenaga kesehatan tradisional dan tenaga kesehatan lain. Seharusnya dengan adanya undang-undang tersebut, tenaga medis akan dapat memahami identitas profesi masing-masing.

Identitas profesi yang baik akan mempengaruhi kolaborasi. Penelitian terdahulu menyatakan bahwa kolaborasi interprofesi yang baik akan berpengaruh terhadap kepuasan kerja tenaga medis ${ }^{14}$. Selain tentunya juga akan mempunyai dampak berupa peningkatan kualitas pelayanan kesehatan ${ }^{1}$. 
Dalam upaya mengembangkan identitas profesi, dapat dilakukan dengan pengembangan secara personal, professional dan praktik refleksi diri ${ }^{15}$.

Lama kerja tidak berpengaruh secara signifikan terhadap sikap interprofessional collaboration. Hampir semua tenaga medis yang saat ini bekerja di institusi pelayanan kesehatan, berasal dari kurikulum yang belum mengajarkan interprofessional education. Penelitian di Swedia menyatakan bahwa perawat lulusan dari institusi pendidikan dengan kurikulum IPE merasakan bahwa telah dipersiapkan oleh institusi pendidikan untuk dapat bekerja bersama profesi lain dibandingkan lulusan kurikulum non IPE ${ }^{8}$. Penelitian lain pada mahasiswa tujuh profesi kesehatan, yaitu kedokteran, keperawatan, okupasi terapi, farmasi, fisioterapi, pekerja sosial dan speech language pathology, menemukan bahwa semua mahasiswa merasakan pentingnya kerjasama antar profesi dalam pelayanan pasien dan semua pendidikan profesi kesehatan harus memberikan kesempatan pada mahasiswa untuk mengembangkan kemampuan, perilaku dan sikap yang dibutuhkan dalam kolaborasi antar profesi kesehatan ${ }^{16}$. Pendekatan komunitas memberikan pengalaman yang berbeda dibanding pengalaman klinik mahasiswa. Ketrampilan yang dilatih dengan pendekatan tersebut adalah komunikasi massa, complex team management, kepemimpinan, dan dampak langsung pada stakeholders serta masyarakat ${ }^{17}$. Pembekalan pembelajaran IPE dengan pendekatan komunitas ini akan dapat meningkatkan kemampuan kolaborasi lulusan, terutama yang akan bekerja di komunitas misalnya Puskesmas.

Keterbatasan studi ini adalah hanya menggunakan dua Puskesmas, karena terbatasnya pendanaan. Selain itu teknik sampling yang digunakan adalah purposif sampling. Adanya keterbatasan ini menyebabkan hasil studi ini masih terbatas untuk digeneralisasikan.

\section{KESIMPULAN}

Persepsi tenaga kesehatan tentang identitas profesi mempengaruhi sikap tentang identitas profesi. Perlu memperkuat persepsi tenaga kesehatan tentang identitas profesi.

\section{UCAPAN TERIMA KASIH}

Penelitian ini dapat terlaksana dengan baik karena peran dan bantuan dari berbagai pihak yang telah membantu baik secara langsung maupun tidak langsung, untuk itu peneliti mengucapkan terimakasih kepada:

1. Rektor Universitas Sebelas Maret Surakarta

2. Ketua LPPM UNS

3. Puskesmas Kratonan dan Banyuanyar

4. Semua Pihak yang telah membantu dalam penyusunan laporan ini

\section{DAFTAR PUSTAKA}

1. WHO. 2013. Interprofessional Colaborative Practice in Primary Health Care. Nursing and Midwifery Perspective. Six Case Studies. Human Resources For Health Observer. 13(4)

2. Thislethwaite, J. 2012. Interprofessional education: a review of context, learning and the research agenda. Med Educ. 2012 Jan;46(1):58-70. doi: 10.1111/j.13652923.2011.04143.x

3. Blue, AV, Mitcham, M, Smith, T, Raymond, J, Greenberg, R. 2010. Changing the Future of Health Professions: Embedding Interprofessional Education Within an Academic Health Center. Academic Medicine. Vol 85 (8)

4. WHO. 2010. Framework for action on interprofessional education and collaborative practice, World Heatlh Organization.

5. Oeseburg, B, Hilberts, R, Luten, TA, Van Etten AVM, Slaet JPJ, Roodbol, P. 2013. Interprofessional education in primary care for the elderly: a pilot study. BMC Medical Education. 13:161

6. Thistlethwaite, J, Moran, M. 2010. Learning outcomes for interprofessional education 
(IPE): Literature review and synthesis. Journal of Interprofessional Care. Vol 24(5): 503-513

7. Hamid, etal. 2016. Interprofessional communication and interprofessional collaboration among health care professional. The European proceedings of social and behavioural sciences EpSBS.

8. Wilhelmsson, M, Svensson, A, Timpka, T, Faresjö, T. 2013. Nurses views of interprofessional education and collaboration: A comparative study of recent graduates from three universities. Journal of Interprofessional Care. (27), 2, 155-160.

9. Braithwaite J, etal, 2012. A four-year, systems-wide intervention promoting interprofessional collaboration. BMC Health Serv Res. doi: 10.1186/1472-6963-12-99.

10. Pemerintah Negara Republik Indonesia. 2014. Undang-Undang no 36 tahun 2014 tentang Tenaga Kesehatan.

11. Pemerintah Negara Republik Indonesia. 2004. Undang-Undang no 29 tahun 2004 tentang Praktik Kedokteran

12. Pemerintah Negara Republik Indonesia. 2019. Undang-Undang no 4 tahun 2019 tentang Kebidanan

13. Pemerintah Negara Republik Indonesia. 2014. Undang-Undang no 38 tahun 2014 tentang Keperawatan

14. Korner, M, Goritz, AS, Bengel, J. 2019. Healthcare professionals' evaluation of interprofessional teamwork and job satisfaction. Evaluation der Teamarbeit und der Arbeitszufriedenheit von Gesundheitsfachberufen. International Journal of Health Professions. Volume 1, Issue 1, 2014, Pages 5-12, ISSN 2296990X, DOI: 10.2478/ijhp-2014-0006

15. Mat Nor, MZ. 2019. Contribution of faculty developmental programmes to professional identity development of medical educators in Malaysia: A phenomenological study. Journal of Taibah University Medical Sciences (2019) 14(4), 324-331

16. Lumague, M, Morgan A, Mak, D, Hanna, M, Kwong, J, Cameron, C, Zener, D, Sinclair, L. 2006. Interprofessional education: The student perspective. Journal of Interprofessional Care, Vol 20(3): 246 - 253

17. Bridge, Diane. Davidson, Richard. Odegard, Peggy S. Maki, Ian, et al. 2011. Interprofessional collaboration: three best practice models of interprofessional education. Medical Education Online, 16: 6035-DOI: 10.3402/meo.v16i0.6035 